\title{
Dynamic boil-off characterization for discharge process of LNG vehicle tank
}

\author{
Deng, Pingping; Liang, Jierong; Wu, Yongqiang; Li, Tingxun
}

\section{Published in:}

Energy

Link to article, DOI:

10.1016/j.energy.2019.07.143

Publication date:

2019

Document Version

Peer reviewed version

Link back to DTU Orbit

Citation (APA):

Deng, P., Liang, J., Wu, Y., \& Li, T. (2019). Dynamic boil-off characterization for discharge process of LNG vehicle tank. Energy, 186, [115813]. https://doi.org/10.1016/j.energy.2019.07.143

\section{General rights}

Copyright and moral rights for the publications made accessible in the public portal are retained by the authors and/or other copyright owners and it is a condition of accessing publications that users recognise and abide by the legal requirements associated with these rights.

- Users may download and print one copy of any publication from the public portal for the purpose of private study or research.

- You may not further distribute the material or use it for any profit-making activity or commercial gain

- You may freely distribute the URL identifying the publication in the public portal

If you believe that this document breaches copyright please contact us providing details, and we will remove access to the work immediately and investigate your claim 


\title{
Dynamic Boil-off Characterization for Discharge Process of LNG Vehicle Tank
}

\author{
Pingping Deng a,1, Jierong Liang ${ }^{\mathrm{b}, 1}$, Yongqiang $\mathrm{Wu}^{\mathrm{c}, 2}$, Tingxun $\mathrm{Li}^{\mathrm{a},{ }^{*}}$ \\ a School of Engineering, Sun Yat-sen University, West XINGANG Road 135, Guangzhou 510275, China \\ ${ }^{\mathrm{b}}$ Department of Energy Conversion and Storage, Technical University of Denmark, 4000 Roskilde, Denmark

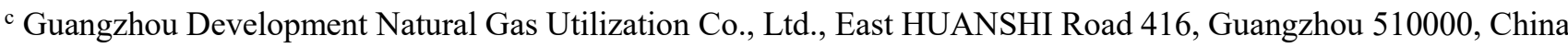 \\ *Corresponding author. Tel.: +86 02039331115. \\ ${ }^{1}$ P.D. and J.L. contributed equally. \\ E-mail address: Litx@hotmail.com (Tingxun Li),Litx@mail.sysu.edu.cn. \\ Postal address: No. 135, Xingang West Rd., Guangzhou City 510275, Guangdong PR China.
}

\begin{abstract}
:
This study aims to find the optimal boil-off gas (BOG) recovery procedure during the regular LNG vehicle tank maintenance. The BOG discharge process links to rapid depressurization and other important physical characteristics. We set up a full-scale field prototype and test on different initial working conditions. A numerical model was developed accounting for fluid mechanics, interphase heat and mass transfer, which had been verified with the experiments. Based on experimental results and model predictions, we characterized the instantaneous thermodynamic properties of BOG and the relationship between discharge mass and discharge time. In practical situations, spending too much time in BOG recovering would affect the regular maintenances of the vehicle tank. Designing a reasonable recovery time for each tank is crucial to achieve the maximum BOG recovery efficiency. Finally, the mappings of recovery time and the equivalent recovery rate under different initial conditions are established to guide the design of practical operating scheme.
\end{abstract}

Keywords: LNG vehicle tanks, boil-off gas (BOG), discharging, recovery

\section{Introduction}

Natural gas as the clean fuel, is growingly demanded in trucking and marine in the form of LNG [1, 2], China has about 230 thousand LNG vehicles currently. The number of LNG vehicles is expected to reach 1.5 million by 2020 [3]. For some practical reasons, certain BOG had to be discharged into the atmosphere, resulting in higher operating costs and air pollution. According to the Global Warming Potential (GWP), methane (the major component in LNG mixtures) emissions contributed the climate impact of up to 72 times than that caused by $\mathrm{CO}_{2}$ in the recent [4]. Recovering the BOG to the extent possible will be great beneficial to the environmental and economic issues. The discharge scenarios related to the LNG vehicle tanks are mainly classified into: (1) testing the static evaporation rate, (2) maintaining constant pressure during the storage and transportation, or (3) discharging when safety valves or other parts are repaired. This study located at the BOG recovery of the aforementioned scenario (3). For safety considerations, the LNG vehicles tanks are required to conduct the regular maintenance periodically. Before maintenance, the vehicle tanks need to be depressurized to the atmospheric pressure. The remaining liquid is allowed to store inside; but the gas is discharged and pollutes the air. Our solution is collecting the BOG gas and delivering it to the city gas network. In the practical situations, the time cost for the recovery has affected the maintenance procedure. It is valuable to design the scientific recovery time to balance the competition of time cost and recovery benefits. Accurately predicting the recoverable BOG amount and the discharge time will guide the recovery program technically.

The distinctive features of the BOG discharge process of vehicle tank were summarized as following. (1) Strong 
transient processes are concerning due to small volume of tank and short discharge time. (2) Interface heat and mass transfer dominate the discharge process because of the short time. (3) The total relative discharge mass is small due to different operating conditions, which are only $7 \%-20 \%$ as shown in section 4.2 . To the authors' knowledge, few studies had been found directly link to the dynamic characterization of the LNG vehicle tanks discharge process. In addition, due to its hazardous nature and the high capital costs, experimental data related to the discharge of hydrocarboncontaining mixtures are often difficult to obtain [5]. In recent decades, there are a number of experiments in LNG movement characterization, such as land-based storage tanks outflow [6], spill on land or water, the spill boil-off rates $[6,7]$, rapid phase transitions [8,9], pressurized releases [10] and pool fires [11,12]. However, these experiments are considering the impact of the uncertainties on the LNG operation risks, rather than studying the physical phenomena. Relevant experiments mainly focused on the LNG weathering with approximately isobaric process during maritime transportation [13] and storage [14-16]. In discharge process of vehicle tank, transient depressurization is a key factor. Clear technical gap still exists between the vehicle tank discharge and weathering. Common hydrocarbons depressurization data is reported to optimize the vessel design [17,18], but the experiments were pursuing the correct and reliable minimum wall and fluid temperatures. Therefore, in-depth dynamic discharge characterizations for the small size tank are still relative lacking and valuable to carry out. To contribute the LNG recovery program practically during the vehicle maintenance, sensitive studies and evaluations of recovery versus time expenditure were investigated from the attested numerical modelling tools.

Comparing with the LNG weathering model in the situations of maritime transportation $[19,20]$ and storage tanks [21-23], the isobaric assumptions are not suitable in this study. Early researches are focusing on pure gas discharge processes using both adiabatic and isothermal models [24]. Several non-equilibrium models [25-30] and commercial software packages [31-32] are developed (Table 1) to prevent the wall temperature of the vessel from falling below the ductile-brittle transition temperature of the steel during the depressurization processes [33]. The model BLOWDOWN studied the dynamic effects of different initial components on wall temperatures and different discharge positions. Speranza and Terenzi (2005) [29] introduced the concept of Partial Phase Equilibrium to account for the interphase mass and energy transfer. D'Alessandro et al. (2015) [30] improved the Partial Phase Equilibrium model to reduce the complexity and computational time. Park et al. (2018) [34,35] developed a model including multi-layer transient conduction, combined natural and forced convection, and nucleate boiling at the vessel surface based on the aforementioned models. The existing model details and modelling requirements in this study were comparative analyzed in Table 1. The most distinctive features between this study and existing models are the research insights on strong depressurization process and relations of pressure, mass and discharge time based on different initial conditions. In practical situation of this project, spending too much time in BOG recovering would affect the regular maintenances of the vehicle tank. Designing a reasonable recovery time for each tank is important to balance the recovery ratio and discharge time. Based on the model built in this study, an evaluation system is defined to determine the optimal operating conditions.

In this paper, the full-scale field prototype experiments under different conditions were carried out to characterize the transient rapid depressurization process. A numerical model for BOG discharging was developed to predict the total mass of recoverable BOG and the discharge time. Finally, an evaluation scheme was established to find the maximum BOG recovery during a reasonable period. 
Table 1

The main features of the existing numerical models and the requirements of modelling in this study

\begin{tabular}{|c|c|c|c|}
\hline Aspects & References & Descriptions & Requirements in this study \\
\hline \multirow{3}{*}{ LNG weathering } & $\begin{array}{l}\text { Miana et al. }[13,20] \\
\text { Pellegrini et al. }[14]\end{array}$ & $\begin{array}{l}\text { - Assumed the pressure inside the } \\
\text { tank is constant }\end{array}$ & - Rapid depressurization process \\
\hline & $\begin{array}{l}\text { Chen et al. [15] } \\
\text { Dimopoulos GG. [19] }\end{array}$ & $\begin{array}{l}\text { - Analyzed different mechanisms of } \\
\text { heat leak }\end{array}$ & $\begin{array}{l}\text { - A numerical model to predict the total mass of } \\
\text { recoverable BOG and the required discharge }\end{array}$ \\
\hline & $\begin{array}{l}\text { Adom E. [21] } \\
\text { Migliore et al. [22,23] }\end{array}$ & $\begin{array}{l}\text { - Analyzed the effect of the } \\
\text { nitrogen content on the BOG rate }\end{array}$ & $\begin{array}{l}\text { - Instantaneous pressure, fluid temperature and } \\
\text { mass flow rate }\end{array}$ \\
\hline Pure gas discharge & Dutton J C. [24] & - adiabatic or isothermal & - Two-phase fluid in non-equilibrium \\
\hline \multirow[b]{2}{*}{$\begin{array}{l}\text { Blowdown of } \\
\text { pressure vessels }\end{array}$} & $\begin{array}{l}\text { Haque et al. }[25,26] \\
\text { Overa et al. }[27]\end{array}$ & $\begin{array}{l}\text { - Complex two-phase transition } \\
\text { model }\end{array}$ & - Simplified gas-liquid mass transfer \\
\hline & $\begin{array}{l}\text { Mahgerefteh et al. [5,28] } \\
\text { Speranza et al. [29] } \\
\text { D'Alessandro et al. }\lceil 30\rceil \\
\text { Park et al. }[34,36]\end{array}$ & $\begin{array}{l}\text { - Safety considerations on the } \\
\text { lowest wall temperature during } \\
\text { the depressurization process }\end{array}$ & $\begin{array}{l}\text { - Finding an optimum operating condition to } \\
\text { ensure that balance recovery and discharge time }\end{array}$ \\
\hline
\end{tabular}

\section{Full-scale field test apparatus}

The experiments were carried out at the Donghui LNG station at Guangzhou (China) using an LNG vehicle tank with double-layered insulation under high vacuum [36]. The inner tank was used to store LNG, and the maximum allowable working pressure (MAWP) was $1600 \mathrm{kPa}$. The tank was immersed in freely-convecting air at $293.15 \mathrm{~K}$, thus the liquidvapor phases, i.e., $\mathrm{LNG}$ and $\mathrm{BOG}$ were in equilibrium before the vent valve is opened.

Fig.1 shows the full-scale field prototype test rig and the diagram of the experimental system. During the discharge process, BOG flowed from the tank outlet to the BOG management area through the Coriolis mass flowmeter installed in the LNG dispenser, as shown in Fig.1 (a). Fig.1 (b) shows the pre-cooling process of LNG tank before filling the liquid. Experiments under different initial pressures and liquid levels were carried out by controlling LNG charge volumes and re-cooling the tank. In addition, BOG discharging under different valve openings was achieved by adjusting the flow area of FT in Fig. 1 (c). The pressure transmitter PT-1 installed behind the valve VV was monitoring the internal pressure in the tank. The level of the liquid inside the tank was measured by the level transmitter LT, and the flowmeter transmitter FT was adopted to measure the discharge mass flow rate. The specifications of the instruments and the tank used listed in Table 2. Before the experiments, the valves of SV, FCV, and GV, were in an open state, and then the tank was allowed to stabilize for about 1 hour after filled with liquid from the LNG dispenser. Once the initial working condition is reached, the valve VV is opened and the experimental data of BOG discharging are collected in the meantime. 


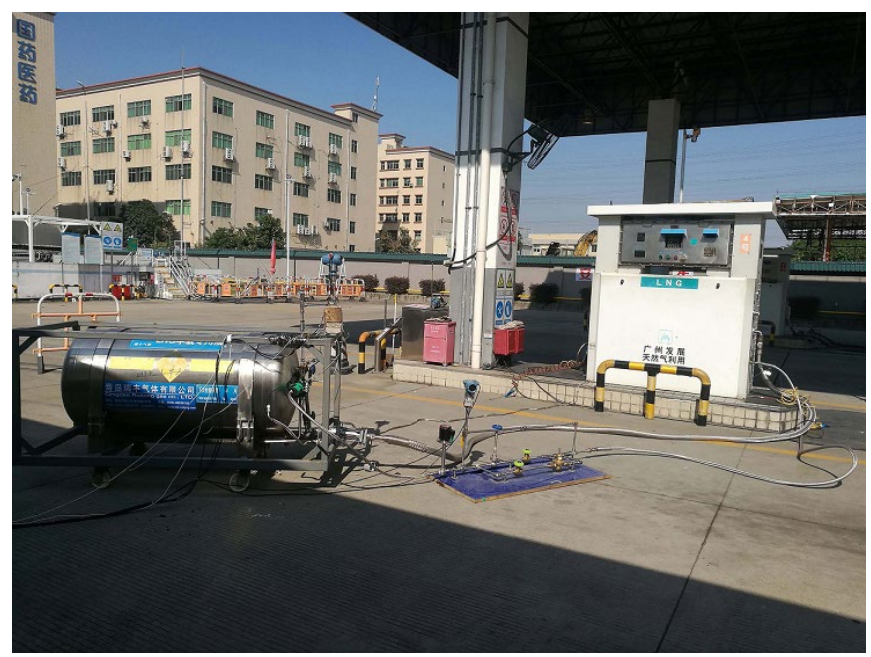

(a)

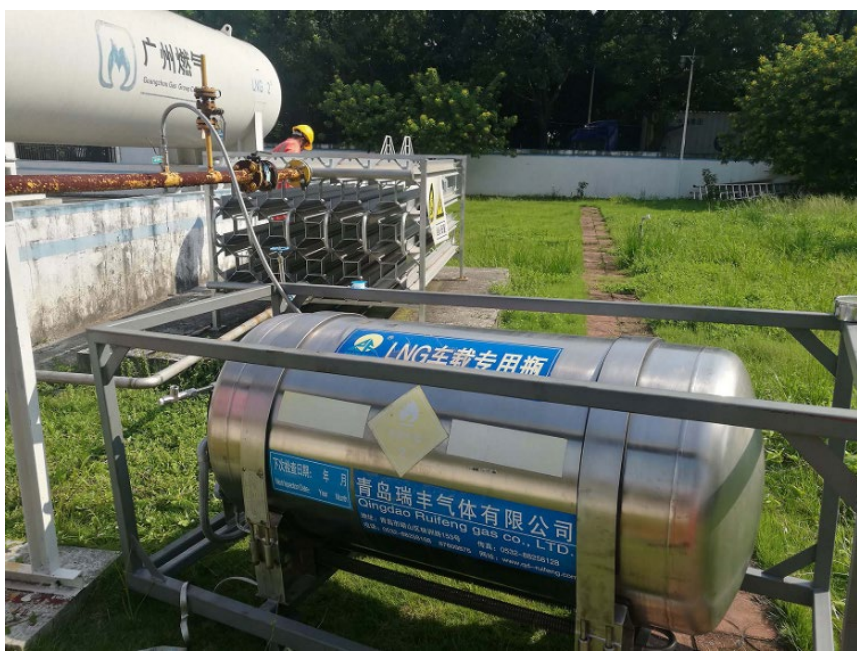

(b)

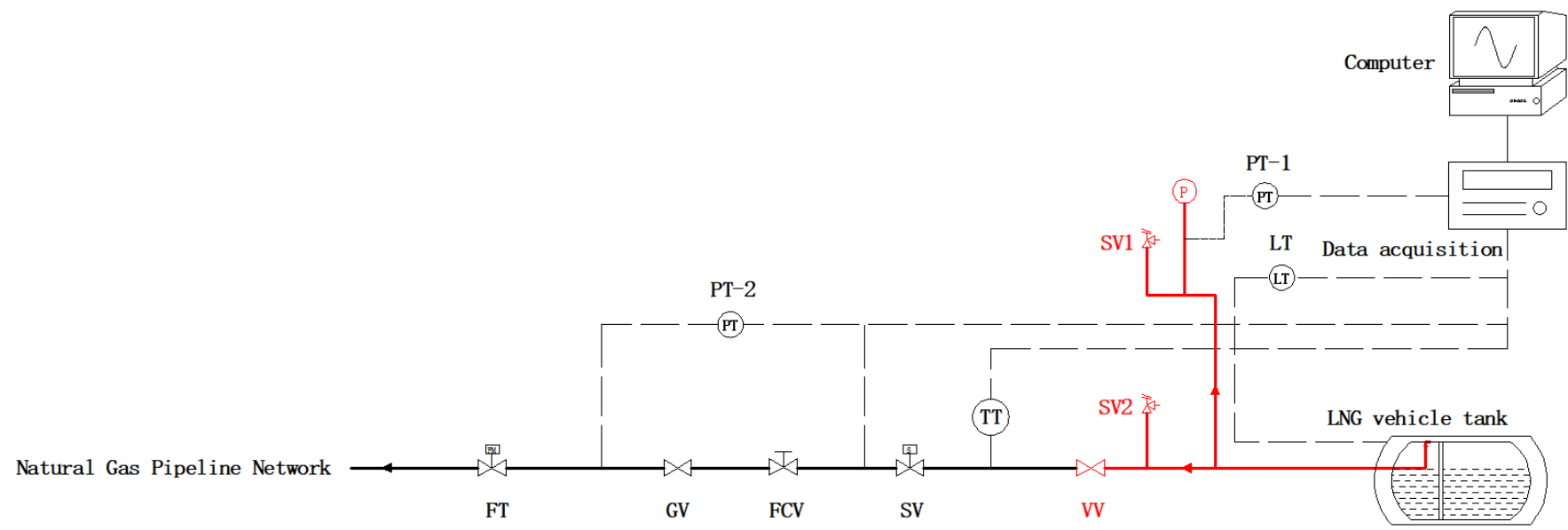

(c)

Fig.1. Experiment illustration:(a) Full-scale field prototype test rig, (b) LNG vehicle tank and (c) The diagram of experimental system (PT-1/2: Pressure transmitter; LT: Level transmitter; SV1: Primary safety valve; SV2: Secondary safety valve; VV: Vent valve; TT: Temperature transmitter; SV: Solenoid valve; FCV: Flow control valve; GV : Globe valve; FT: Flowmeter transmitter)

Table 2

Equipment Specification

\begin{tabular}{lllll}
\hline Equipment & Spec & Value & Precision & Manufacturer \\
\hline Tank & Length $\times$ Diameter & $1.516 \times 0.658$ & - & Qingdao Ruifeng Gas Co., Ltd \\
Pressure transmitter & 3051TG & $0-4 \mathrm{MPa}$ & $\pm 0.14 \%$ & Emerson \\
Flowmeter transmitter & CMF025M300NRAPMZCX & $0-18.14 \mathrm{~kg} / \mathrm{min}$ & $\pm 0.03 \%$ & Emerson \\
Level transmitter & Tran-4.2vout-H & $0-0.6 \mathrm{~m}$ & $\pm 2 \%$ & Shenzhen Arctic King Tortop Technology Co.,Ltd \\
Data acquisition & MX100 & Speed 2.4ch/ms & - & Yokogawa \\
\hline
\end{tabular}

\section{Numerical model}

The thermodynamic model included the conservations of mass and energy, heat and mass transfer equations and equations of state, which aimed to predict the instantaneous parameters such as pressure, the remaining mass, and the mass flow rate. The modelling system showed in Fig.2 can be divided into: (1) vapor control volume (BOG), (2) liquid control volume (LNG), (3) interphase heat and mass transfer $\left(\dot{\mathrm{Q}}_{\mathrm{VL}}\right.$ and $\left.\dot{\mathrm{m}}_{\mathrm{EVA}}\right),(4)$ discharge flow $\left(\dot{\mathrm{m}}_{\mathrm{EMIT}}\right),(5)$ heat leaks from vapor phase $\left(\dot{\mathrm{Q}}_{\mathrm{V}, \text { in }}\right)$ 
and (6) heat leaks from liquid phase $\left(\dot{Q}_{\mathrm{L}, \text { in }}\right)$. Thermodynamic properties were obtained from a thermophysical property package based on Helmholtz free energy. The following control equations were transformed in a set of first-order differential equations, the gas and liquid properties and pressure interval were determined between the time steps.

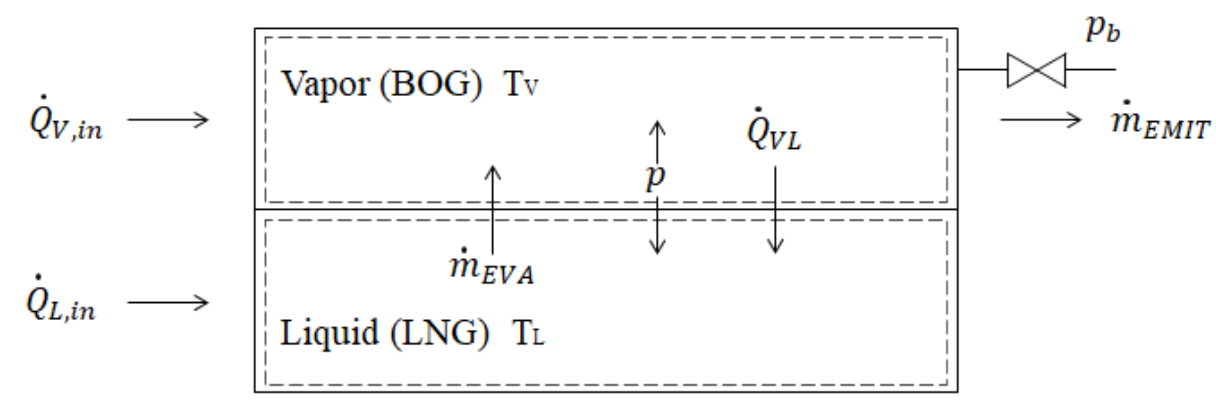

Fig.2. Schematic of model elements

\subsection{Model assumptions}

The modelling assumptions were made as following.

1. The temperature and composition in each fluid phase were assumed to be spatially uniform, and the pressure was assumed to be spatially uniform in the tank, as suggested by different authors: Haque et al [26], Mahgerefteh and Wong [28], Speranza and Terenzi [29], Valerio D'Alessandro et al [30].

2. The evaporative BOG migrated completely into the bulk gas region, immediately after forming.

3. The flow through the valve is one-dimensional.

4. Valve flow coefficient and overall heat transfer coefficients due to heat leak were considered as constant, which was fitted by the experimental data.

\subsection{Control equations}

The total mass balance for the whole system is given by:

$\frac{d\left(M_{V}\right)}{d t}+\frac{d\left(M_{L}\right)}{d t}=-\dot{m}_{E M I T}$

Where $\mathrm{M}_{V}$ and $\mathrm{M}_{\mathrm{L}}$ are the mass of the vapor and liquid subsystem, respectively. $\dot{\mathrm{m}}_{\mathrm{EMIT}}$ is the discharge mass rate through the vent valve.

The volume of the tank is constant, we have:

$\frac{d V_{V}}{d t}+\frac{d V_{L}}{d t}=0$

Where $\mathrm{V}$ is the volume of the tank, and the subscripts $\mathrm{V}$ and $\mathrm{L}$ indicate vapor and liquid, respectively.

\subsubsection{Liquid subsystem}

The mass balance in LNG domain (liquid phase) is given by:

$\frac{d\left(M_{L}\right)}{d t}=-\dot{m}_{E V A}$

Where $\dot{\mathrm{m}}_{\mathrm{EVA}}$ is the net rate of evaporation, which is calculated by:

$\dot{m}_{E V A}=\frac{M_{L} \times \varepsilon}{\tau}$

Where $\varepsilon$ indicates the vapor fraction of vapor-liquid phase produced when the liquid phase is heated, which is based on energy conservation and calculated by a thermophysical property package; $\tau$ is the net evaporation relaxation time, which is derived from Ref.[37]. The evaporation rate was dependent of the liquid mass inventory within the steam accumulator, determined by the latent heat and the enthalpy difference of the liquid phase. In this study, $\tau$ is treated as an empirical parameter and will be fitted in section 4.1. 
The following energy balance is required for the liquid subsystem:

$\dot{Q}_{L, i n}+\dot{Q}_{V L}=\frac{d\left(M_{L} h_{L}\right)}{d t}+\dot{m}_{E V A} h_{V}\left(T_{S}, p\right)$

Where $\dot{Q}_{L, \text { in }}$ and $\dot{Q}_{V L}$ are the heat leak rate from liquid phase and the interphase heat flux, respectively. $h_{L}$ is the enthalpy of liquid phase, $T_{S}$ is the saturated temperature corresponding to the pressure $p$, and $h_{V}\left(T_{S}, p\right)$ is the saturated enthalpy of the evaporated vapor.

\subsubsection{Vapor subsystem}

The following energy balance is required for the vapor subsystem:

$\dot{Q}_{V, \text { in }}-\dot{Q}_{V L}=\frac{d\left(M_{V} h_{V}\right)}{d t}+\dot{m}_{E M I T} h_{V}\left(T_{V}, p\right)-\dot{m}_{E V A} h_{V}\left(T_{S}, p\right)$

Where $\dot{Q}_{V, \text { in }}$ is the heat leak rate from vapor phase, and $h_{V}$ is the enthalpy of the vapor phase. $T_{V}$ is the vapor temperature; $\mathrm{h}_{\mathrm{V}}\left(\mathrm{T}_{\mathrm{V}}, \mathrm{p}\right)$ is the enthalpy of the vapor phase.

\subsubsection{Heat transfer calculation}

The heat transfer from the external environment to the inside of the tank, including convection and heat conduction, can be characterized by a total heat transfer equation. The heat flux through the entire tank wall and between phases is treated as follows [23]:

$\dot{Q}_{V, \text { in }}=U_{\text {dry }} A_{\text {dry }}\left(T_{\text {air }}-T_{V}\right)$

$\dot{Q}_{L, \text { in }}=U_{\text {wet }} A_{\text {wet }}\left(T_{\text {air }}-T_{L}\right)$

$\dot{Q}_{V L}=\dot{Q}_{\text {sen }}+\dot{Q}_{\text {lat }}=\underbrace{h A_{V L}\left(T_{V}-T_{L}\right)}_{\text {Sensible heat }}+\underbrace{\dot{m}_{E V A}\left(h_{V}\left(T_{S}, p\right)-h_{L}\left(T_{S}, p\right)\right)}_{\text {Latent heat }}$

Where T denotes temperature, and the subscripts V, L and air indicates vapor, liquid and the surrounding, respectively; $A_{d r y}$ and $A_{w e t}$ are the inside surface of the tank filled with liquid and vapor, respectively; $A_{V L}$ is the vapor-liquid contact area. $\mathrm{U}$ is the overall heat transfer coefficient. In this study, $U_{\text {dry }}$ and $U_{\text {wet }}$ are empirical parameters to be fitted in section 4.1. $\dot{\mathrm{Q}}_{\text {sen }}$ and $\dot{\mathrm{Q}}_{\text {lat }}$ are the interphase sensible heat and latent heat flux, respectively; $\mathrm{h}_{\mathrm{L}}\left(\mathrm{T}_{\mathrm{S}}, \mathrm{p}\right)$ is the saturated enthalpy of the liquid phase; $h$ denotes the convection heat transfer coefficient between vapor and liquid phase. For convective heat transfer, the empirical relationship from Kozanoglu and Rubio [38,39] is used:

$N u=0.116 R a^{0.32}$

The Nusselt number $(\mathrm{Nu})$ and Rayleigh number $(\mathrm{Ra})$ are given by:

$N u=\frac{h L}{k}$

$R a=\frac{g \rho_{V}^{2} \beta_{V}\left(T_{V}-T_{L}\right) L^{3} c_{p, V}}{\mu_{V} k_{V}}$

Where $\mathrm{g}, \rho, \beta, \mathrm{c}_{\mathrm{p}}, \mathrm{k}$, and $\mu$ are gravitational constant, density, thermal expansion coefficient, specific heat, thermal conductivity and dynamic viscosity, respectively. The subscripts $\mathrm{V}$ and L indicate vapor and liquid phase, respectively; All the mentioned parameters in Eq.(10)-(12) are calculated by a thermophysical property package.

The characteristic length $\mathrm{L}$ is given by:

$L=0.00082 R a^{0.31}$

Which can be made explicitly by combining with Eq.(10), Eq.(11), Eq.(12) and Eq.(13):

$h=\frac{N u \cdot k}{L}=6.7296588 \cdot k^{0.857144} \cdot\left(\frac{g \rho_{V}^{2} \beta_{V}\left(T_{V}-T_{L}\right) c_{p, V}}{\mu_{V}}\right)^{0.142856}$

The geometry of the tank is simplified to a straight horizontal tank with flat ends, the contact area varied with the liquid level.

$\theta=\arccos \frac{H-R}{R}$ 
$A_{\text {wet }}=2 R \cdot[L(\pi-\theta)+R(\pi-\theta)+(H-R) \cdot \sin \theta]$

$A_{\text {dry }}=2 \pi R^{2}+2 \pi R L-A_{\text {wet }}$

$A_{V L}=2 L \cdot \sqrt{R^{2}-(R-H)^{2}}$

Where $\mathrm{R}$ is the tank radius, $\mathrm{H}$ is the liquid level, and $\mathrm{L}$ is the horizontal length of the tank.

\subsubsection{Discharge calculation}

The mass flow rate through the valve can be calculated by assuming incompressible flow:

$-\dot{m}_{E M I T}=C_{d} A\left[2 \rho_{V}\left(p-p_{b}\right)\right]^{1 / 2}$

Where $C_{d}$ is the valve flow coefficient, which was fitted in section 4.1. A indicates the throttling flow area of the valve, $\mathrm{p}_{\mathrm{b}}$ is the back pressure, $\mathrm{p}$ denotes the pressure in the tank.

\subsection{Logic sequence of solution}

The execution logic flow of the model consisted of initial estimation, thermodynamic property calculation in each phase, convergence check and variable update. Control equations above were solved using the finite difference method. In each time step, a series of iteration sequences are shown in Fig.3.

Initial variables consist of temperature $\mathrm{T}$, pressure $\mathrm{p}$, environment temperature $\mathrm{T}_{\text {air }}$, liquid level $\mathrm{H}$, atmospheric pressure $\mathrm{P}_{0}$, tank size $\mathrm{L}$ and $\mathrm{R}$, valve opening $\mathrm{S}$ and other initial thermodynamic parameters. TQFLSH, TPFLSH and PHFLSH are thermophysical property packages for updating the thermodynamic properties. At the beginning of current time step, we estimate a pseudo pressure value $\left(\mathrm{p}^{\prime}\right)$ to go through the control equations. The discharge mass flow rate $\left(\dot{\mathrm{m}}_{\mathrm{EMIT}}{ }^{\prime}\right)$ can be derived by a sequence of property solutions. On the other hand, we solve the valve sub-model in Eq.(19) to get the same variable $\dot{\mathrm{m}}_{\text {EMIT }}$. By equalizing $\dot{\mathrm{m}}_{\mathrm{EMIT}}{ }^{\prime}$ and $\dot{\mathrm{m}}_{\mathrm{EMIT}}$, the convergent value of $\mathrm{p}^{\prime}$ can be determined and set as the pseudo value in next time step. Consequently, all the parameters in current time step can be updated based on the convergent $\mathrm{p}^{\prime}$. The default program would terminate when reaching the steady state $\left(p=p_{b}\right)$. 


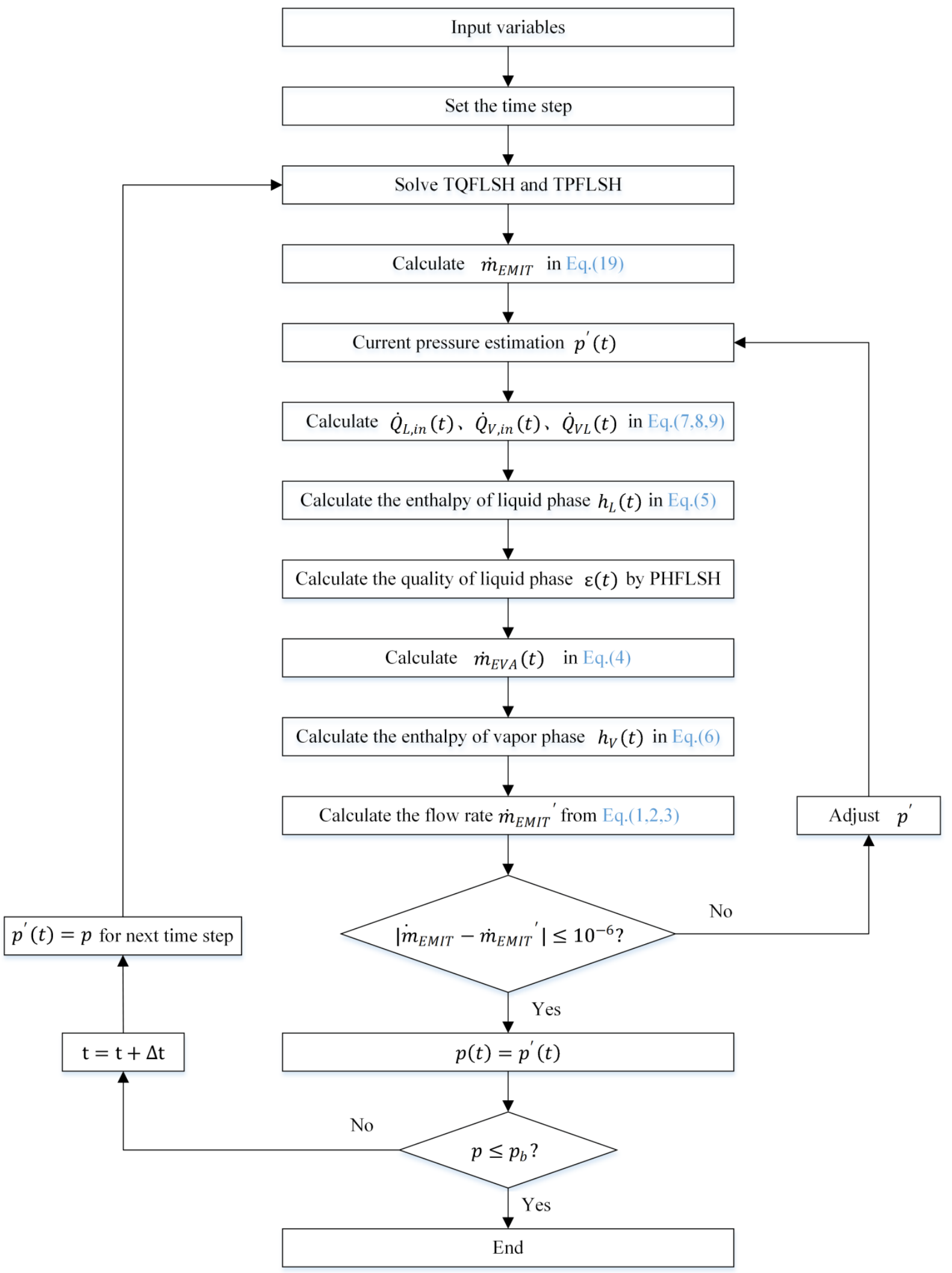

Fig.3. Iteration sequence in each time step

\section{Results and discussion}

\subsection{Parameter fitting and model validation}


For the purpose of the following model analysis, we went through the parameter fitting, balance confirmation and result comparison orderly.

Empirical parameters here are $C_{d}, \tau, U_{d r y}$ and $U_{w e t}$ referring to the above Eq.(19,4,7,8). According to relevance analysis, empirical parameters are fitted using individual data set. Specifically, $C_{d}$ fit came from the relationship of pressure drop and flowrate $\left(\mathrm{p}\left(\dot{\mathrm{m}}_{\text {EMIT }}\right)-\mathrm{p}_{\mathrm{b}}\left(\dot{\mathrm{m}}_{\mathrm{EMIT}}\right)\right)$ in valve sub-model; $\tau$ fit was running based on the curves of pressure and flow rate histories $\left(p(t)\right.$ and $\left.\dot{\mathrm{m}}_{\mathrm{EMIT}}(\mathrm{t})\right)$. $\mathrm{U}_{\text {dry }}$ and $\mathrm{U}_{\text {wet }}$ derived their initial values from Ref. [40] and fit in the curve of pressure history $(\mathrm{p}(\mathrm{t}))$. It should be noted that the portion of heat leaks $\left(\dot{\mathrm{Q}}_{\mathrm{V}, \text { in }}\right.$ and $\left.\dot{\mathrm{Q}}_{\mathrm{L}, \text { in }}\right)$ play a minor role, which is estimated $5 \%$ contribution in this situation. Then $U_{d r y}$ and $U_{\text {wet }}$ fit would not change a lot from their initial values. In this sense, $C_{d}$ and $\tau$ fits were carried out firstly based on the initial $U_{d r y}$ and $U_{\text {wet }}$. Subsequently, $U_{d r y}$ and $U_{\text {wet }}$ were adjusted to get the curve of $\mathrm{p}(\mathrm{t})$ further approaching to the experimental data. The values of empirical parameters are listed in Table 3 .

Table 3

Summary of empirical parameters. The variation of convection heat transfer coefficient $\mathrm{h}$ is due to the temporal change and different working conditions. The largest value is observed at the beginning of discharge process. The zero value is captured at the end and equivalent state of discharge process. $\mathrm{U}_{\mathrm{dry}}, \mathrm{U}_{\mathrm{wet}}, \tau$ and $\mathrm{C}_{\mathrm{d}}$ are treated as constants.

\begin{tabular}{lccc}
\hline Parameter & Symbol & Unit & Values \\
\hline Overall heat transfer coefficient & $\mathrm{U}_{\mathrm{dry}}, \mathrm{U}_{\text {wet }}$ & $\mathrm{W} /(\mathrm{m} \cdot \mathrm{k})$ & 0.03 \\
Convection heat transfer coefficient & $\mathrm{h}$ & $\mathrm{W} /\left(\mathrm{m}^{2} \cdot k\right)$ & $0-10$ \\
Net evaporation relaxation time & $\tau$ & $\mathrm{s}$ & 1.428 \\
Valve flow coefficient & $\mathrm{C}_{\mathrm{d}}$ & - & 0.65 \\
\hline
\end{tabular}

Balance confirmation is a variance calculation based on mass and energy conservation (Eq.(1-6)) at each time step:

$$
\begin{aligned}
& \delta M(t)=\underbrace{\frac{d\left(M_{V}\right)}{d t}+\frac{d\left(M_{L}\right)}{d t}}_{\text {Mass storage }}+\underbrace{\dot{m}_{E M I T}}_{\text {Mass outflow }} \\
& \delta E(t)=\underbrace{\frac{d\left(M_{V} h_{V}\right)}{d t}+\frac{d\left(M_{L} h_{L}\right)}{d t}}_{\text {Energy storage }}+\underbrace{\dot{m}_{E M I T} h_{V}\left(T_{V}, P\right)}_{\text {Energy outflow }}-\underbrace{\left(\dot{Q}_{V, \text { in }}+\dot{Q}_{L, \text { in }}\right)}_{\text {Energy inflow }}
\end{aligned}
$$

According to the calculations of total mass variance $(\delta \mathrm{M}(\mathrm{t}))$ and energy variance $(\delta \mathrm{E}(\mathrm{t}))$, the maximum deviation is within the order of $10^{-12}$. Thus, the model framework is mass and energy convergent.

The result validation was operating under different initial pressures and liquid levels, based on the same valve opening $(100 \%)$, surrounding temperature $(293 \mathrm{~K})$ and backpressure $(101 \mathrm{kPa})$, which was shown in Fig.4. Note that the standard deviations from experimental are calculated to be $\pm 0.96 \mathrm{~kg} / \mathrm{min}$ in flow rate, $\pm 5.81 \mathrm{kPa}$ in pressure and $\pm 0.013 \mathrm{~m}$ in liquid level. In Fig.4 (a), we observed less than 7.8\% deviation of flowrate at the beginning stage, and the maximum error of 5\% during the remaining time. The reason of the small uneven deviation distribution was due to some strong transient phenomena that unconsidered in the model, as empirical fitting merely minimized the differences between model and experiment in overall. In the cases of pressure and liquid level comparisons (Fig.4 (b) and (c)), experimental data were located within the error of $3.5 \%$ and $4.86 \%$, respectively. In summary, the model was well validated to predict detailed LNG characteristics in BOG discharging process. Although the liquid measurements fluctuate in a certain range, the model predictions fitted well. From the regular observations, the liquid level fluctuations during the discharge processes but also at steady state. This was probably caused by small value of relative permittivity in cryogenic liquid [41]. Note that adopting capacitive level gauge was considering the situations of anti-explosive and relative high pressure. 


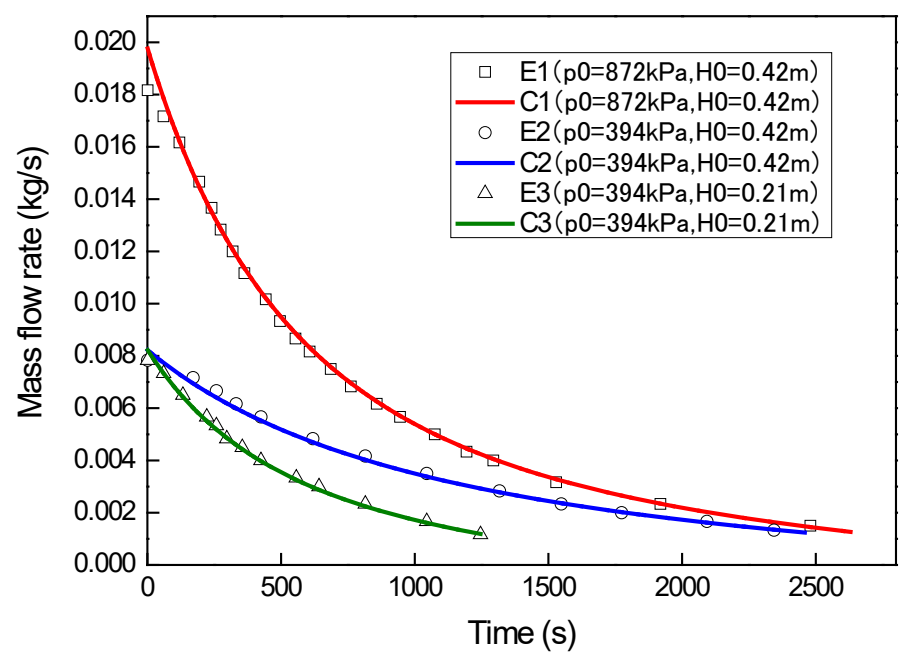

(a)

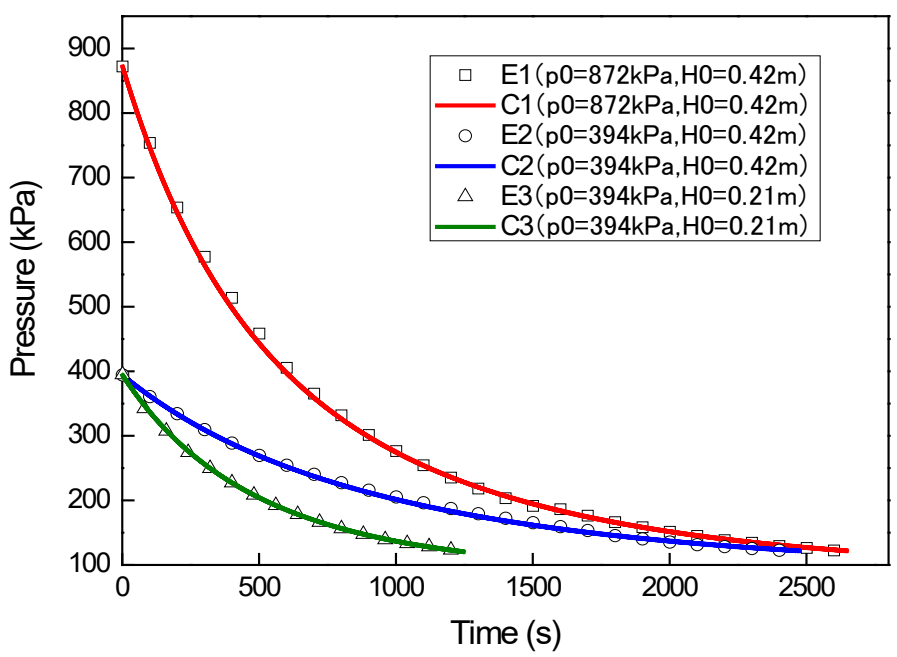

(b)

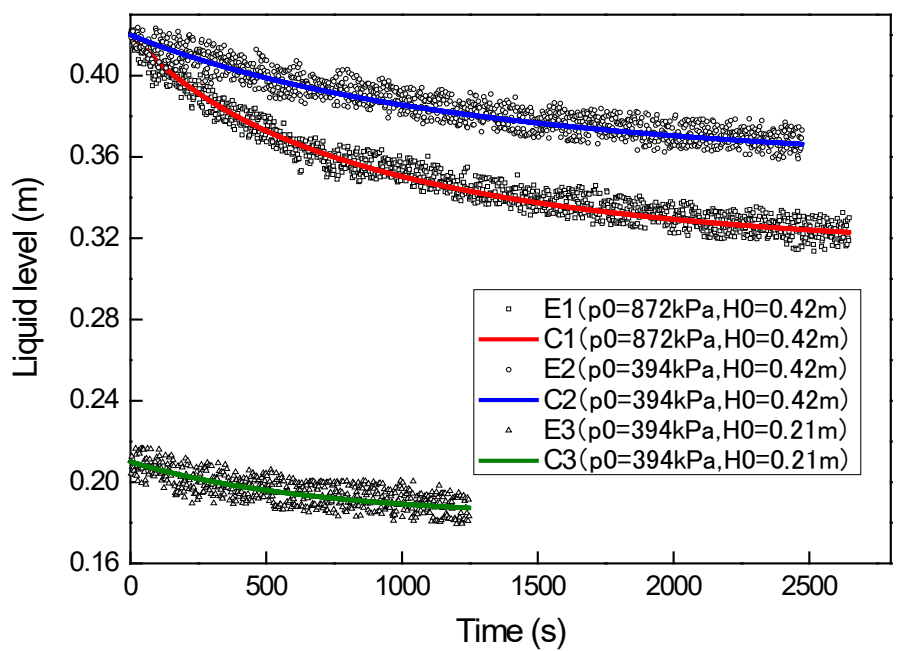

(c)

Fig.4. Modelling and experiment comparisons in (a) mass flow rate, (b) tank pressure and (c) liquid level. E and C are standing for experiment and model; p0 and $\mathrm{H} 0$ are standing for initial pressure and liquid level.

\subsection{Dynamic characterizations of BOG discharge process}

Based on the model predictions, the impact factors of valve opening, initial pressure and liquid level on the discharge characterization are studied in Fig.5. The valve opening is linearly proportional to the flow area of cross-section. Therefore, the opening is the representative of the BOG flow area. The surrounding temperature and backpressure were set at $293.15 \mathrm{~K}$ and $101 \mathrm{kPa}$, respectively. The analyzing period was from the vent valve started opening to that the pressure dropped to the atmospheric pressure.

The relationships of discharge time, discharge mass and valve opening are crucial to determine the optimal discharge process. Fig.5 (a) illustrated the behaviors of the pressure change under different selected valve openings. In BOG recovery processes that will be discussed in section 4.3 , the dynamic pressure characterization is important for estimating the residual pressure before releasing the BOG. In general, the pressure decline in each curve has gone through from rapid to slow. Specifically, the pressure variation with the valve opening $30-50 \%$ is much more significant than that with the valve opening $10-30 \%$. With the opening enlarging, the impacts of the valve opening become insensitive to the discharge process. Fig.5 (b) provided the discharge time characterizations under different initial pressures and liquid levels. In overall, the discharge time increased dramatically with the valve opening decreased; but became insensitive when the opening is large enough. Between different initial conditions, liquid level impact is rather more significant than pressure impact on discharge time. Therefore, liquid level is the key factor to determine the discharge time. Fig.5 (c) revealed the relationship of relative mass flow rate and 
relative remaining mass under different valve openings. The mass flow rate is linearly proportional to the remaining mass of LNG for all curves; while the slope of the line increased dramatically with the valve opening increased. Since LNG weight is not convenient in practical BOG recovery process, the linear characterization of remaining mass and BOG flow rate would help estimating the recovery amount simultaneously. Fig.5 (d) presented the relative remaining mass characterizations under different initial conditions. The relative discharge mass are located between 7\%-20\%. High liquid level and low initial pressure led to the relative low discharge ratio. Based on the discharging process with unlimited time, the discharge ratio is almost independent of valve opening. In this situation, we cannot recover more LNG vapor by only adjusting the valve opening. In BOG recovery processes as in section 4.3 , there will be an external piping that generating extra backpressure and reducing the discharge time. As shown in Fig. 5 (e), the discharge time is linearly proportional to the length of piping. Discharge system with external piping for recovery would take longer than direct emissions; the extra time can also be estimated via this linear relationship.

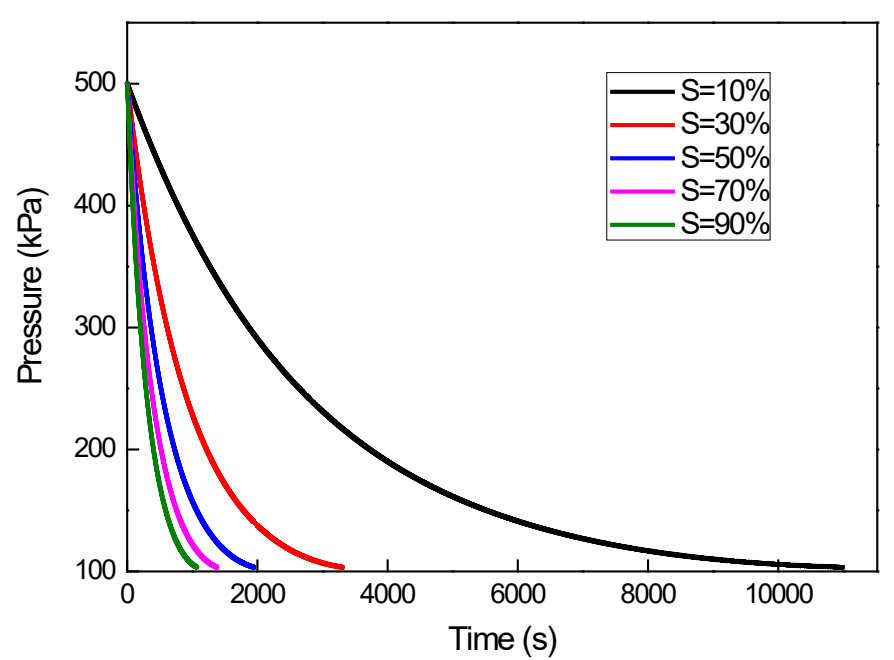

(a)

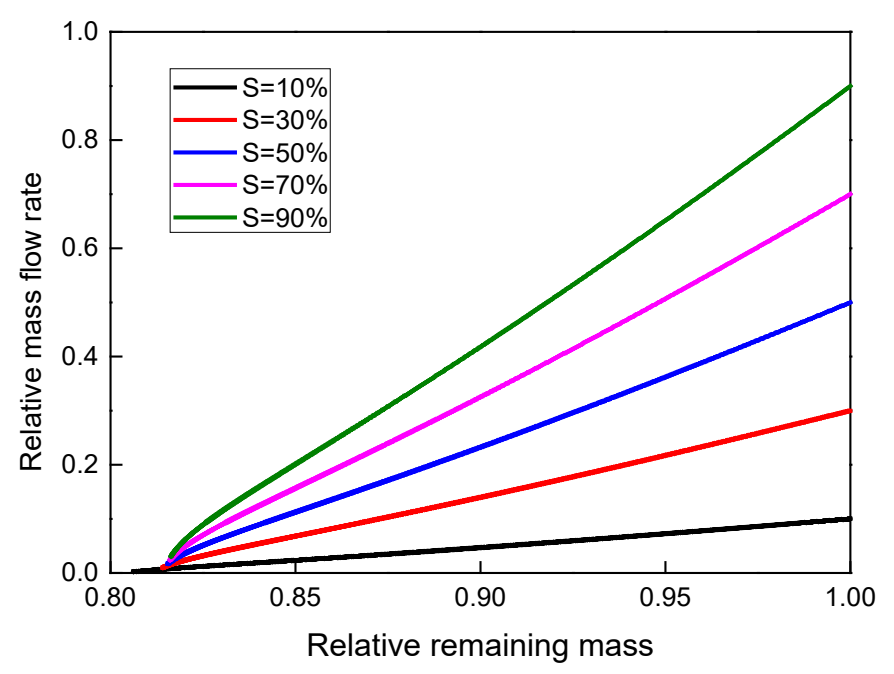

(c)

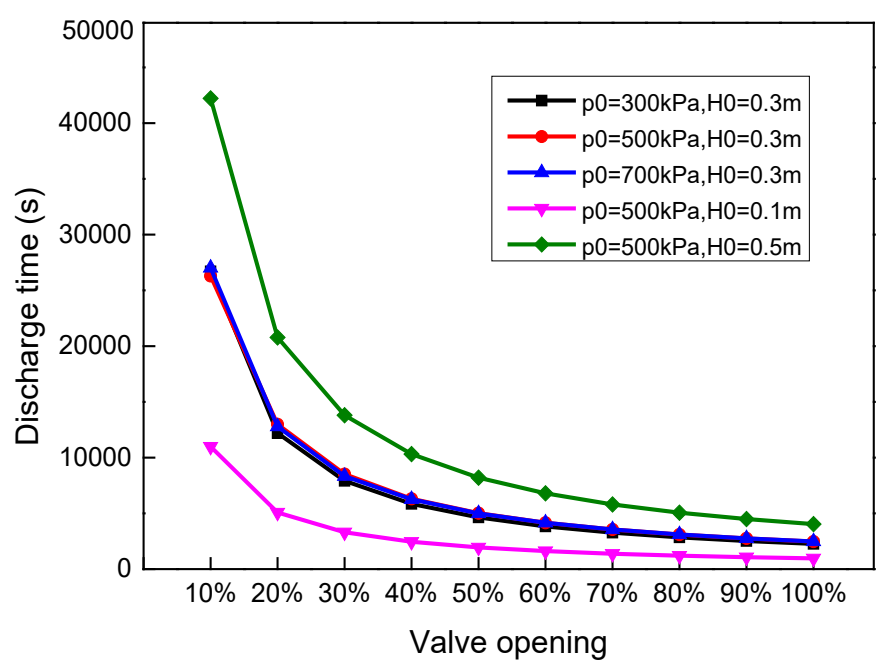

(b)

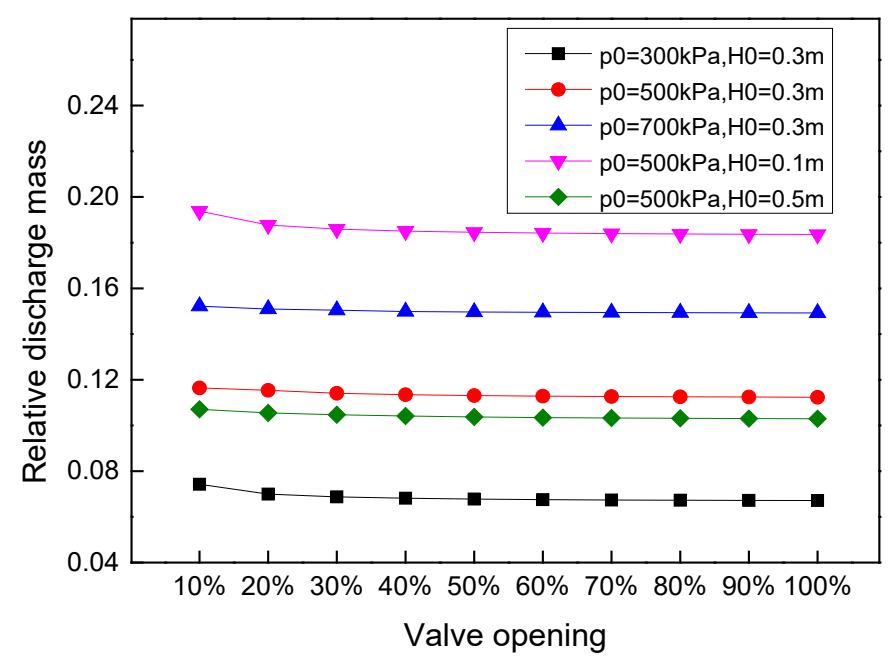

(d) 


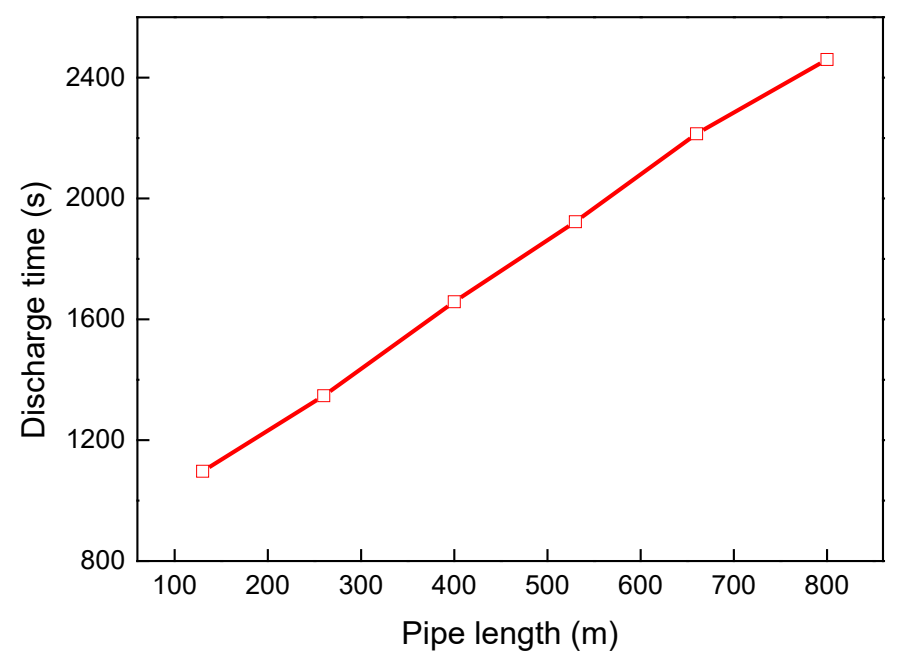

(e)

Fig.5. Discharge characterizations based on model predictions. (a) Pressure change versus time with different valve openings under the initial condition of $\mathrm{p} 0=500 \mathrm{kPa}$ and $\mathrm{H} 0=0.1 \mathrm{~m}$; (b) Discharge time versus valve opening under different initial conditions; (c) Relationships between relative remaining mass and relative mass flow rate under the initial condition of $\mathrm{p} 0=500 \mathrm{kPa}$ and $\mathrm{H} 0=0.1 \mathrm{~m}$; (d) Discharge ratio versus valve opening under different initial conditions; (e) Discharge time versus external pipe length of recovery system under the initial condition of $\mathrm{p} 0=500 \mathrm{kPa}$ and $\mathrm{H} 0=0.1 \mathrm{~m}$. The relative remaining mass is defined as the ratio of the remaining to the initial LNG mass. The relative mass flow rate is defined as the ratio of the mass flow rate to the initial mass flow rate based on $100 \%$ valve opening. The relative discharge mass is defined as the discharge BOG to the initial LNG mass.

\subsection{Recovery procedure optimization}

This project aims to recover maximal BOG by connecting the discharge outlet to LNG networks. Due to the long-distance external piping system and the discharge characterizations in section 4.2, the recovery time was too long to meet the requirement of the regular LNG tank maintenance. We have to give up some recoveries to make the tank depressurized to atmosphere and ready for the maintenance procedure, which is illustrated in Fig.6 in detail.

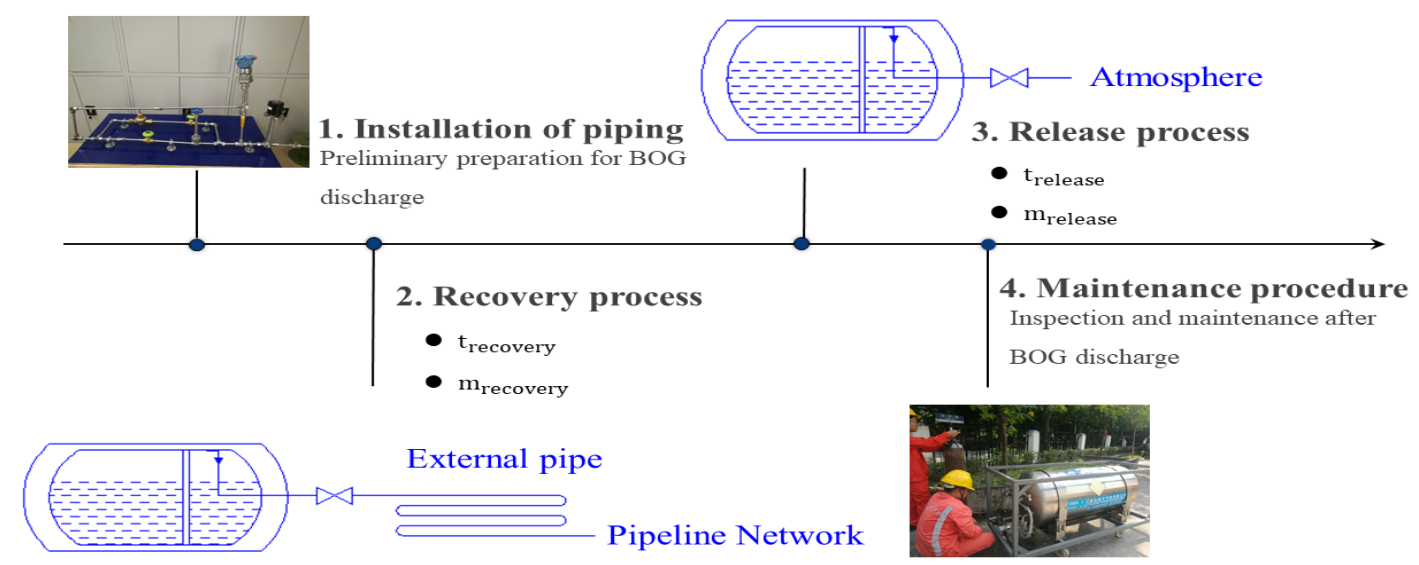

Fig.6. Schematic of maintenance process of LNG vehicle tank

To quantify this situation, the discharge mass $\left(\mathrm{m}_{\text {discharge }}\right)$ is defined as the combination of the recovery mass $\left(\mathrm{m}_{\text {recovery }}\right)$ and the release mass $\left(\mathrm{m}_{\text {release }}\right)$. In the release process, the BOG is allowed to flow out without going through the piping to reach a significant short discharge time. Accordingly, the discharge time $\left(t_{\text {discharge }}\right)$ also consists of the recovery time $\left(t_{\text {recovery }}\right)$ and the release time $\left(t_{\text {release }}\right)$. Fig. 7 revealed the mapping relations of liquid level, $t_{\text {recovery }}, t_{\text {release }}$, recovery ratio $(\varphi)$, and $\mathrm{t}_{\text {discharge. }}$. The $\varphi$ was defined as the ratio of $\mathrm{m}_{\text {recovery }}$ to $\mathrm{m}_{\text {discharge }}$. 
$m_{\text {discharge }}=m_{\text {recovery }}+m_{\text {release }}$

$t_{\text {discharge }}=t_{\text {recovery }}+t_{\text {release }}$

$\varphi=m_{\text {recovery }} / m_{\text {discharge }}$

From Fig.7 (a), the $\varphi$ was increasing monotonously with the $t_{\text {recovery }}$, and decreasing with the liquid level. Based on the same liquid level, $\varphi$ and $t_{\text {recovery }}$ are intuitively competitive factors during the BOG recovery process. The relationships among $t_{\text {recovery }}, t_{\text {release }}$ and $t_{\text {discharge }}$ were illustrated in Fig.7 (b) and (c). The $t_{\text {release }}$ was found to decrease almost linearly with the increase of $t_{\text {recovery }}$ in different initial conditions. Meanwhile, the $t_{\text {discharge }}$ linearly increased with the $t_{\text {recovery }}$ increase. Consequently, BOG recovery optimization is essentially the suitable trade-off between the $\varphi$ and the $t_{\text {discharge. }}$ On the other hand, the discharge mass with the recovery time deviated the linear relation and the change rate declined. That meant the recovery ratio is limited after certain long recovery time. Designing the reasonable $t_{\text {recovery }}$ was beneficial to the practical vehicle BOG recovery. In order to combine the $\varphi$ and $t_{\text {recovery }}$ into a single performance metric, the equivalent recovery rate (ERR) was defined as:

$E R R=\varphi / t_{\text {discharge }}$

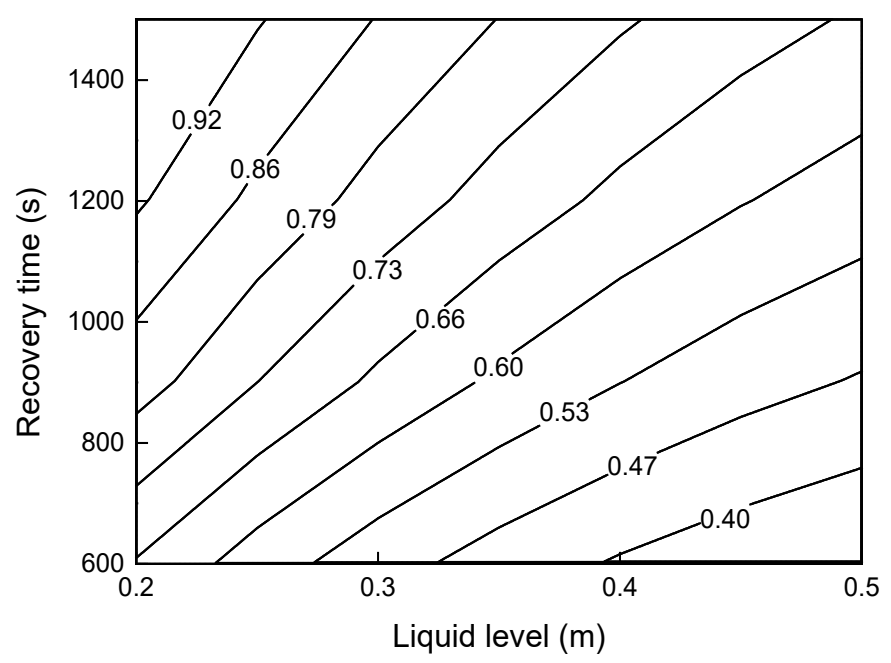

(a)

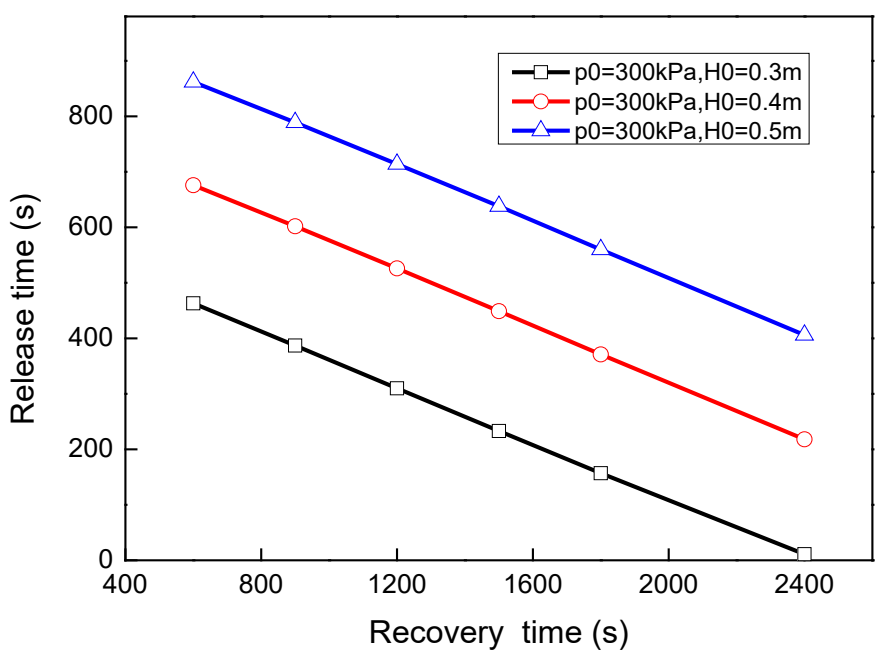

(b)

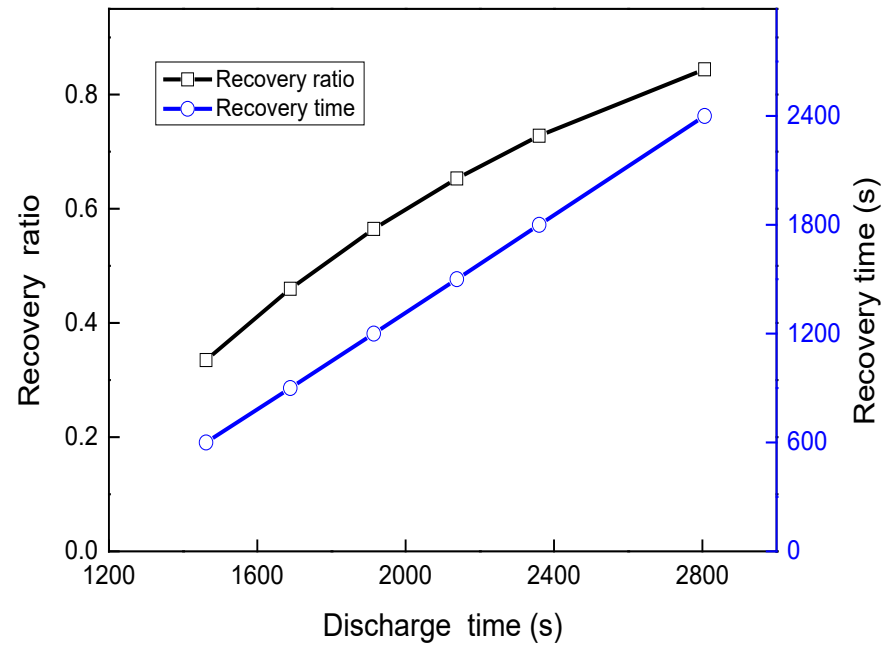

(c)

Fig.7. Modelling analysis in (a) contour lines of recovery rate $(\varphi)$ as a function of recovery time and initial liquid level at $\mathrm{p} 0=300 \mathrm{kPa}$, (b) relationship between recovery time and release time, and (c) the relationships of recovery ratio, recovery time and discharge time under the initial condition of $\mathrm{p} 0=300 \mathrm{kPa}$ and $\mathrm{H} 0=0.5 \mathrm{~m}$. 
The BOG recovery optimization is referring to the issues of pursuing a maximal ERR with the $t_{\text {discharge }}$ constraint. The ERR was strong dependent of the $t_{\text {recovery }}$ and related to the operating conditions. Initial liquid level and pressure are important parameters for the operating conditions. Fig. 8 presented the ERR and $t_{\text {discharge }}$ characteristics based on $100 \%$ valve opening over different discharge conditions. From these mapping charts, relevant engineers can figure out the maximum ERR and reasonable $t_{\text {discharge }}$ based on the current operating conditions. The initial pressure posed a slightly negative effect on the ERR, while the liquid level had a significant influence on the ERR and $t_{\text {discharge }}$. Therefore, the recovery performance was partially determined by the status of the incoming LNG vehicle tank. Based on a certain low liquid level $(<\sim 65 \%)$, the ERR increased with the $t_{\text {recovery }}$; then went to a flat region with approximately constant values; finally, the ERR decreased with the $t_{\text {recovery. }}$. For practical issues, $t_{\text {recovery }}$ design should focus on the transition of the increase region and the flat region (optimal points). In the cases of high liquid level, the optimal points shifted to the high value of the discharge time that might locate outside the range of the figure. In actual recovery process, when the operating conditions of the tank are known, the engineers can obtain the optimal $t_{\text {recovery }}$ from these mapping charts for the purpose of limiting the $t_{\text {discharge }}$ and maximizing the total daily recovery.

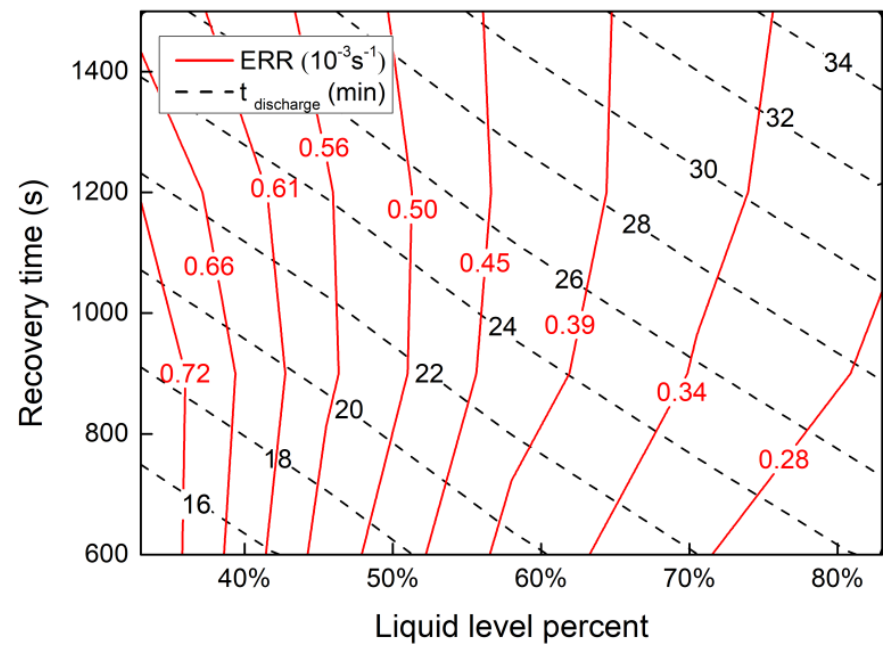

(a)

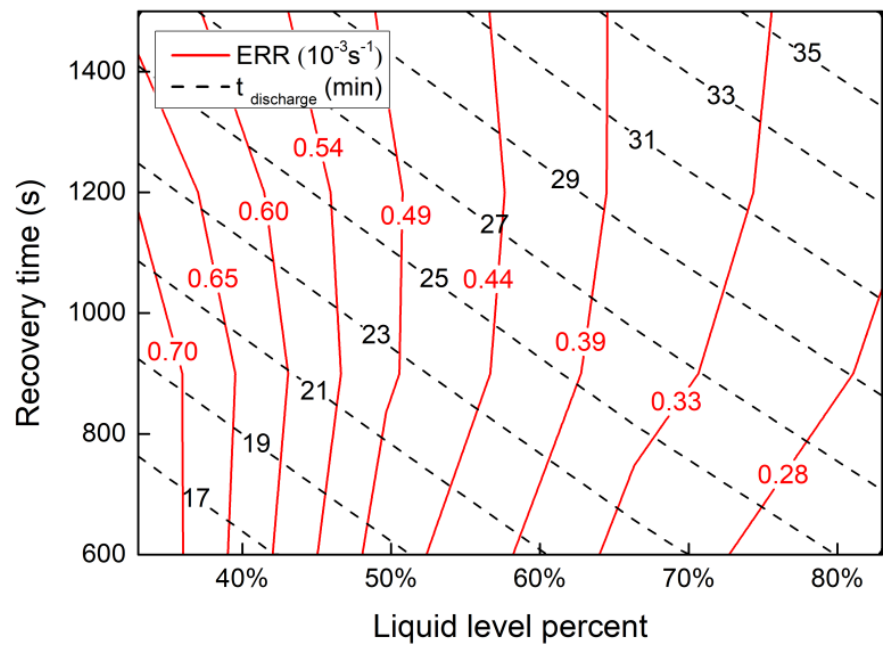

(b)

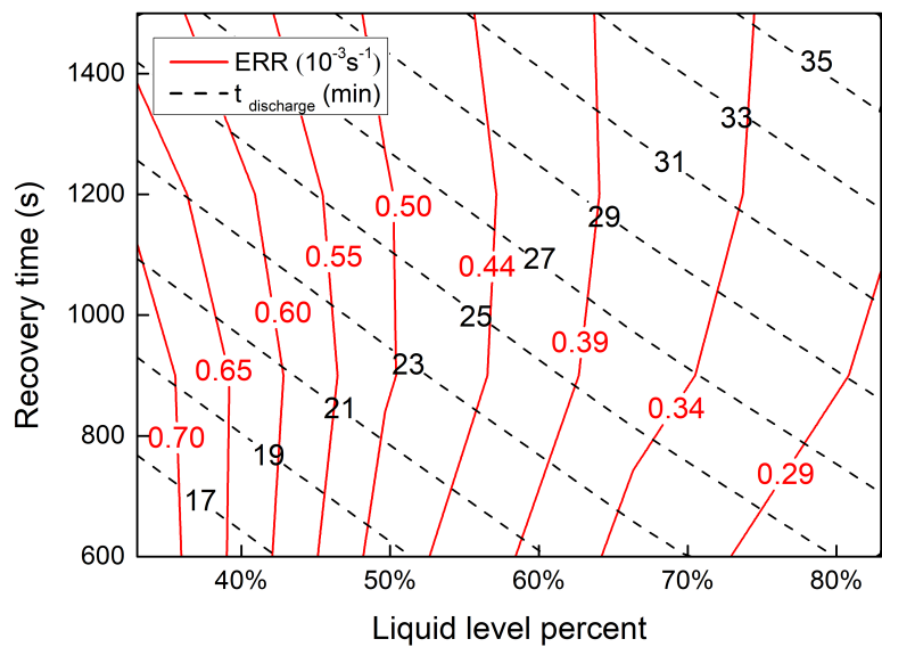

(c)

Fig.8. Lines of constant equivalent recovery rate (ERR) and discharge time $\left(t_{\text {discharge }}\right)$ as a function of recovery time $\left(t_{\text {recovery }}\right)$ and initial liquid level in (a) $\mathrm{p} 0=300 \mathrm{kPa}$, (b) $\mathrm{p} 0=400 \mathrm{kPa}$, (c) $\mathrm{p} 0=500 \mathrm{kPa}$

\section{Conclusion}

Based on the scenario of LNG recovery in maintenance processes of vehicle tank, dynamic discharge were characterized. In the situations of small size tank and strong transient depressurization, full-scale field prototype experiments and the 
corresponding model were developed. The empirical parameters were fitted and the model was validated by the experiments. The relationships of instantaneous discharge mass and discharge time were analyzed and concluded as:

(1) During the discharge processes, the factors of valve opening, initial pressure and initial liquid level have different impacts. Valve opening is critical to affect the discharge time, but the impacts of the valve opening become insensitive when the opening is large enough. Liquid level impact is rather more significant than pressure impact on discharge time.

(2) Some similar regularities are found between different discharge processes. The relative mass flow rate is linearly proportional to the relative remaining mass. Regardless of any initial state and valve opening within the practical range, the final relative discharge mass was varying from $7 \%$ to $20 \%$. High recovery ratio was located at the conditions of high pressure and low liquid level.

(3) In order to meet the time requirement of the regular LNG tank maintenance, an evaluation system was established to balance the recovery ratio and the discharge time. For the objectives of gaining maximum recovery ratio in limited discharge time, there is an optimal recovery point at each initial condition. The critical factor is the initial liquid level rather than initial pressure. When the liquid level increase, the optimal point normally shifts to high value of the discharge time.

The main achievements of this study were to obtain the optimum recovery time during the regular LNG vehicle tank maintenance, which can provide time schedule for engineers to conduct the subsequent operation. Similarly, it can ensure that the discharge time is within a reasonable range and improve the total mass of recoverable BOG.

\section{Acknowledgments}

J.L. is grateful for financial support of the CSC (China Scholarship Council) scholarship. This work was supported by Guangzhou Development Natural Gas Utilization Co., Ltd (China).

\section{Reference:}

[1] International Energy Agency. Gas 2018.Analysis and forecasts to 2023.

[2] BP. BP Energy Outlook 2018 Edition. 2018.

[3] Analysis of Application Status and Development Trend of LNG Industry in 2018. https://www.qianzhan.com/analyst/detail/220/1805091ccd47da.html

[4] Sharafian A, Herrera OE, Mérida W. Performance analysis of liquefied natural gas storage tanks in refueling stations. Journal of Natural Gas Science \& Engineering. 2016; 36:496-509.

[5] Mahgerefteh H, Wong, S.M. A numerical blowdown simulation incorporating cubic equations of state. Computers and Chemical Engineering. 1999;23(9):1309-17.

[6] Moorhouse J, Carpenter R. Factors affecting vapour evolution rates from liquefied gas spills. Report MRS E. 1986;460.

[7] Luketa-Hanlin A. A review of large-scale LNG spills: experiments and modeling. Journal of hazardous materials. 2006;132(2-3):119-40.

[8] Reid RC. Rapid phase transitions from liquid to vapor. Advances in Chemical Engineering: Elsevier; 1983. p. 105-208.

[9] Bubbico R, Salzano E. Acoustic analysis of blast waves produced by rapid phase transition of LNG released on water. Safety Science. 2009;47(4):515-21.

[10] Lowesmith BJ, Hankinson G, Acton M, Chamberlain G. An overview of the nature of hydrocarbon jet fire hazards in the oil and gas industry and a simplified approach to assessing the hazards. Process safety and environmental protection. 2007;85(3):207-20.

[11] Moorhouse J. Scaling criteria for pool fires derived from large-scale experiments. Conference Scaling criteria for pool fires derived from 
large-scale experiments, vol. 71. p. 165-79

[12] Lowesmith B, Moorhouse J, Roberts P. Fire Safety Assessments for LNG Storage Facilities: Institute of Gas Technology, 1992.

[13] Miana M, Hoyo Rd, Rodrigálvarez V, Valdés JR, Llorens R. Calculation models for prediction of Liquefied Natural Gas (LNG) ageing during ship transportation. Applied Energy. 2010;87(5):1687-700.

[14] Pellegrini LA, Moioli S, Brignoli F, Bellini C. LNG Technology: The Weathering in Above-Ground Storage Tanks. Industrial \& Engineering Chemistry Research. 2014;53(10):3931-7.

[15] Chen QS, Wegrzyn J, Prasad V. Analysis of temperature and pressure changes in liquefied natural gas (LNG) cryogenic tanks. Cryogenics. 2004;44(10):701-9.

[16] Kountz KJ. Weathering of LNG in on-board storage tanks. Institute of Gas Technology IGT; 1999. project report $32034-02$.

[17] Haque M, Richardson, S., Saville, G., Chamberlain, G., Shirvill, L. Blowdown of pressure vessels. II. Experimentalvalidation of computer model and case studies. Trans IChemE, Part B, Proc Safe Env Prot. 1992b;70(B1):10-7.

[18] Szczepanski, R. Simulation programs for blowdown of pressure vessels. IChemE SONG Meeting, 1994.

[19] Dimopoulos GG FC. A dynamic model for liquefied natural gas evaporation during marine transportation. Int J of Thermodynamic. 2008;11(3):123-31.

[20] Miana M, del Hoyo R, Rodrigálvarez V. Comparison of evaporation rate and heat flow models for prediction of Liquefied Natural Gas (LNG) ageing during ship transportation. Fuel. 2016; 177:87-106.

[21] Adom E IS, Ji X. Modelling of boil-off gas in LNG tanks A case study. Int J Eng Technol. 2010;2(4):292-6.

[22] Migliore C, Tubilleja C, Vesovic V. Weathering prediction model for stored liquefied natural gas (LNG). Journal of Natural Gas Science and Engineering. 2015; 26:570-80.

[23] Migliore C, Salehi A, Vesovic V. A non-equilibrium approach to modelling the weathering of stored Liquefied Natural Gas (LNG). Energy. 2017; 124:684-92.

[24] Dutton J C CRE. Experiments to study the gaseous discharge and filling of vessels. International Journal of Engineering Education. 1997;13(2):123-34.

[25] Haque MA, Richardson, S.M., Saville, G. \& Chamberlain, G. Rapid depressurization of pressure vessels. Journal of Loss Prevention in the Process Industries. 1990;3(1):4-7.

[26] Haque M, Richardson, S., Saville, G. Blowdown of pressure vessels I. Computer model. Trans IChemE, Part B, Proc Safe Env Prot. 1992a;70(B1):3-9.

[27] Overa, S. J., Stange, E.,Salater, P. Determination of temperatures and flare rates during depressurization and fire. In Proceedings of 72nd GPA Annual Convention, 1994: p. 235-247.

[28] A WM. Development of a mathematical model for blowdown of vessels containing multi-component hydrocarbon mixtures. University of London. 1998.

[29] Speranza A, Terenzi, A. Blowdown of hydrocarbons pressure vessel with partial phase separation. Applied and Industrial Mathematics in Italy. $2005 ; 69: 508$.

[30] D’Alessandro V, Giacchetta G, Leporini M, Marchetti B, Terenzi A. Modelling blowdown of pressure vessels containing two-phase hydrocarbons mixtures with the partial phase equilibrium approach. Chemical Engineering Science. 2015; 126:719-29.

[31] Benjamin F, Souvik, B. Validation of BLOWDOWN Technology in V9 of Aspen HYSYS. 2016.

[32] VESSFIRE. Validation of VessFire Report No.: RP-VessFire-03. http://petrellno/wp-content/uploads/2014/07/Verification-of-VessFirepdf. 2009.

[33] Oster R BK, Kottowski H M. Hydrodynamic considerations of venting with high viscosity non-reacting fluids. Journal of Loss Prevention in the Process Industries. 1990;3(1):50-2.

[34] Park A, Ko Y, Ryu S, Lim Y. Numerical modeling of rapid depressurization of a pressure vessel containing two-phase hydrocarbon mixture. 
Process Safety and Environmental Protection. 2018; 113:343-56.

[35] Ahmin Park YK, Youngsub Lim. A Numerical Simulation of Rapid Depressurization in Pressure Vessels Incorporating Nucleate Boiling of Hydrocarbon Mixture. ASME 2017 36th International Conference on Ocean, Offshore and Arctic Engineering. $2017 ; 1$.

[36] Zhong Y, Fei Y. Research on Materials Corrosion Failure Model of Liquefied Natural Gas (LNG) Tank for Vehicle. Advanced Materials Research. 2013;690-693:3102-7.

[37] Stevanovic VD, Maslovaric B, Prica S. Dynamics of steam accumulation. Applied Thermal Engineering. 2012; 37:73-9.

[38] Kozanoglu B, Rubio F. The characteristic length on natural convection from a horizontal heated plate facing downwards. Thermal Science. 2014;18(2):555-61.

[39] M. C. Heat transfer correlations for free convection from upward-facing horizontal rectangular surfaces. WSEAS Trans Heat Mass Trans. 2007;3(2):48-60.

[40] Saleem A, Farooq S, Karimi IA, Banerjee R. A CFD simulation study of boiling mechanism and BOG generation in a full-scale LNG storage tank. Computers \& Chemical Engineering. 2018;115:112-20.

[41] Karandeev KB, Grinevich FB, Novik AI. Construction of capacitive level gauges. 1961;4(10):835-8. 